\title{
BeIng Just WITH Deconstruction
}

J. M. BALKIN

Yale Law School, USA

$\mathrm{F}$

OR SEVERAL years now I have been concerned with the problem of how one should apply the insights of deconstructive practice to questions of law and justice. This question is far from easy, although many people (in American legal theory, in particular) have simply assumed that deconstruction could readily be adapted to political questions and, in particular, to the political agenda of the left. The problem, however, is that deconstructive techniques do not seem to support any particular vision of justice; indeed they appear to preclude the possibility of any stable conception of the just or the good that could provide the basis for political belief or the authority for political action.

Jacques Derrida's own statements on the relationship between justice and deconstruction have proven somewhat unhelpful. In his most extended discussion of the subject, Derrida insisted simultaneously that (1) justice is impossible (1990:947-9); (2) justice is not deconstructible (1990: 945); (3) law is deconstructible (1990:945); (4) the undeconstructibility of justice and the deconstructibility of law ensure the possibility of deconstruction (1990:945); and (5) deconstruction is justice (1990:945). Taken together, these statements yield a contradiction. ${ }^{1}$

In this essay, I argue for positions developed at greater length elsewhere (see Balkin, 1990a, 1994). First, I claim that deconstructive analyses can be of no use to the pursuit of justice unless deconstructive arguments assume the existence of an alternative which is more just than the one being deconstructed, even if this alternative is subject to further deconstruction. Second, although all conceptions are equally deconstructible, not all are equally just. We must therefore not confuse deconstructability with injustice; our ability to deconstruct a particular

Social \& Legal Studies (SAGE, London, Thousand Oaks and New Delhi), Vol. 3 (1994), 393-404 
legal or social conception without more tells us little about its relative justice or injustice. Third, deconstructive arguments made by human beings are necessarily partial in their target and limited in their scope. As a result, deconstructive argument does not necessarily further the interests of justice but is rather a rhetorical practice that can be used for good or for ill.

Finally, to the extent that deconstructive arguments can be used to criticize law and society as unjust, they must presume the existence of values that transcend the positive norms of human law, culture and convention. Because all positive norms can be deconstructed, the critical use of deconstruction must postulate a transcendental value of justice. Thus, when we employ deconstruction to discuss questions of justice, it becomes what I call transcendental deconstruction. This last conclusion may surprise those devotees of deconstruction who have assimilated the deconstructionist credo (an oxymoron?) that 'there is nothing outside of the text'. I argue that there is indeed something 'outside' - or more correctly 'beyond' - the cultural texts and the positive norms that we deconstruct. This something, and its failure to be adequately captured by our cultural norms is precisely what makes a deconstructive critique of injustice possible.

\section{The Normative Uses of Deconstructive Argument}

I want to begin with a simple question: why might anyone want to deconstruct law or legal doctrine? One reason has to do with the pursuit of justice. We might want to demonstrate that the law or some part of the law is unjust. Alternatively, we might want to show that the law or some part of the law conceals aspects of social life that we believe to be important, and that its failure adequately to deal with these aspects leads to injustice. This is a 'critical' use of deconstruction in a very ordinary sense of that word - it involves pointing out that something is wrong and arguing that it could and should be made better or done better.

It is important to emphasize that legal deconstruction does not have to have a critical purpose. We need not deconstruct legal and social norms in order to criticize the injustices of law or suggest how law and society might be improved. Much literary deconstruction has been devoted to showing the ambiguity, uncertainty and impenetrability of literary texts. So we might deconstruct legal texts as if they were literary texts, and for the same reasons. We might also deconstruct legal texts in order to shake ourselves (and others) out of our accustomed ways of thinking. We might do this because we wish to criticize existing ways of thinking or because we believe that this will save us from a future error or injustice. In that case our purpose is really normative and critical. Nevertheless, it is possible that we are interested in showing the contingency of our beliefs for its own sake.

In addition, we might be interested in showing tensions or contradictions within legal doctrine, but not interested in improving law at all or offering suggestions about how it could be more just. We might believe that it is impossible to improve law or society in any way, and we might wish to show the 
futility of all attempts at doing so. We might want to demonstrate that the entire enterprise of normative legal argument is necessarily incoherent, and that it cannot be made coherent. ${ }^{2}$ Finally, we might simply enjoy showing incoherence and contradiction in social and legal structures; we might find the process of deconstructing aesthetically pleasing but be wholly unconcerned with whether our work has any normative consequences. So there are forms of deconstructive criticism of law that are not 'critical' in my sense of the word.

Although there are many noncritical uses for deconstructive argument, I suspect that deconstruction first attracted many legal and political theorists precisely because they assumed that it could be employed to critique or expose injustices in existing social and legal institutions. Nevertheless, this belief needs to be justified, not merely assumed.

Suppose, then, that we seek to use deconstructive argument to critique law and society for its failure to be fully just. It is by no means clear that deconstruction can assist us in this task. Because all texts are deconstructible, the fact that a conceptual scheme is deconstructible cannot by itself be a reason for rejecting it. Both more and less just conceptions will be equally deconstructible. So we do not yet know how deconstruction assists a critical project. To answer this question, we must decide exactly what we hope to accomplish when we deconstruct a conceptual opposition for a normative purpose.

When we employ deconstruction for a normative purpose, we engage in deconstructive arguments of rectification or amelioration. In other words, we argue that the deconstructed text or conceptual scheme is unacceptable, and that there is a better way of looking at things, even if this conception is in turn subject to further deconstruction. If we do not make these assumptions, then our deconstruction can serve no critical function. It becomes nothing more than the discovery of polysemy and other instabilities of meaning in various conceptual schemes.

All of this may sound so obvious as to be unworthy of mention. Nevertheless, it is important to establish how deconstructive argument can serve a useful normative function. If deconstruction merely discovers instability and incoherence in all texts, then it cannot help us decide that one interpretation is better than another, or that one conceptual scheme is more just than another. So we must make a very significant demand of deconstructive practice before we can hope to make a critical use of deconstructive argument. Indeed, if deconstruction is to be used for rectification or amelioration, deconstructive arguments must do things other than what most people expect them to do. In particular, they cannot be employed to show logical contradiction, semantic incoherence or undecideability.

To see why this is so, let us reexamine what is perhaps the most celebrated example of a deconstructive argument: Jacques Derrida's deconstruction of the distinction between speech and writing in Of Grammatology (1977). Derrida argues that speech and writing are special cases of a more general form of 'writing'. Western philosophers have traditionally assumed that speech is closer to truth or true meaning than writing, but Derrida argues that this is not necessarily so. Both speech and writing possess the same features of signification, which are simply more obvious in the case of writing. 
Derrida uses deconstructive argument to rectify a misconception that he believes many people have held. He offers a deconstructive argument of rectification. He overturns a conceptual hierarchy to reveal something about speech and writing that he claims has been previously overlooked or underappreciated in Western philosophy. He asserts that his is a better way to look at speech and writing than the traditional way, even though his analysis might be subject to further deconstruction. He claims that understanding the semiotic commonality of speech and writing better describes their true nature. If Derrida is not contending that his deconstruction offers a better way of looking at the relation between speech and writing, or better describes their most central and important features, it is hard to understand why he made his argument in the first place. His account would be no better than those of the authors (Plato, Saussure, Rousseau) that he criticizes. Thus, he is not merely saying that we might look at speech and writing as special cases of a more general phenomenon, although we might with equal justification decide not to. He is saying that we should look at them in this way. His argument has a normative import precisely because he believes that there is a better and a worse way to analyze the relationship between writing and speech.

So conceived, deconstructive arguments of rectification are hardly original with Derrida. They appear in the work of Freud, Marx and Hegel, and many other thinkers (see Seung, 1994). Nevertheless, a significant problem remains. The most familiar accounts of how deconstruction works are not consistent with the idea of rectification or amelioration. As I shall now show, each of these accounts proves unacceptable for a critical approach to law.

One view would contend that deconstruction reverses a hierarchy between conceptual opposites, so that the subordinate term is now more important than the superordinate term. However, this will simply lead to an opposite falsification and simplification of the situation. In Derrida's terms, it would simply reestablish the error of logocentrism in a different way; hence in Positions he rejects this interpretation of the deconstruction of the opposition between speech and writing (1981a: 41-2).

A second possibility would be that deconstruction seeks to efface the distinction between the two terms of a conceptual opposition. However, this raises significant problems of its own. We cannot efface the distinction between speech and writing because they are not in fact identical in all respects. Even after our deconstruction, speech is still spoken and writing is still written. Thus, we can only claim that we have effaced the distinction between them if we maintain that the differences between them are unimportant to their true nature. An essential property of speech and writing is their semiotic function; an accidental or inessential property is the fact that they are produced by a voice or with a pencil. However, this commits Derrida to a distinction between essential and inessential properties, a distinction he would be unlikely to adopt. Moreover, it creates a severe irony: we can only justify the effacement of distinctions by asserting the essential character of other properties and distinguishing them from accidental properties. Thus, we efface one distinction only to assert another, necessary one (see Seung, 1994). 
A third approach would argue that deconstruction does not efface the distinction between two opposed terms, but shows rather that each is inherently self-contradictory or incoherent. As applied to a text, it would mean that the text has simultaneously self-contradictory meanings. Thus, our deconstruction of the opposition of speech and writing would show that the concept of speech as a self-present form of signification is self-contradictory. A deconstruction of the Greek word pharmakon (as discussed in Derrida's essay 'Plato's Pharmacy', 1981b) would demonstrate that this word simultaneously means contradictory things (poison and remedy). However, this interpretation of deconstructive practice still cannot assist a critical practice. Because all texts are deconstructible, what can be done to one text can be done to all texts; so all texts will turn out to have simultaneously contradictory meanings. Furthermore, what can be done to one side of a conceptual opposition can be done to the other. Hence both sides of a conceptual opposition will prove self-contradictory and incoherent. Thus, this account of deconstruction shows not only that slavery is internally incoherent, but also freedom. It demonstrates not only that the idea of apartheid is self-contradictory, but also the idea of racial equality.

A fourth interpretation would claim that deconstruction shows the undecideability of the relationship between opposed terms. As a result, we would say that we cannot decide whether speech is closer to truth than writing, writing is closer to truth than speech, or speech and writing are the same thing. We can only oscillate between these different accounts of their relationship. Alternatively, deconstruction would show the undecideability of conflicting meanings of a word. Derrida seems to adopt the idea of undecideability in 'Plato's Pharmacy'; he says that we cannot decide whether the word pharmakon means 'remedy' or 'poison' (1981b:98-9). Nevertheless, the retreat to undecideability is worthless for a critical practice of deconstruction. Undecideability prevents us from calling unjust practices to account, or distinguishing them from just ones. Consider the distinction between apartheid and racial equality. To deconstruct this opposition would mean that we cannot decide whether apartheid is better than racial equality, racial equality is better than apartheid, or racial equality and apartheid are the same thing.

So far, none of the ways of understanding what deconstruction does to a conceptual schema have proved suitable for social or legal critique. Unfortunately, these are the most common interpretations of what deconstruction accomplishes: most people have assumed that deconstruction does show the incoherence or internal inconsistency of conceptual schemes, effaces semantic distinctions, or demonstrates the undecideability of competing interpretations. If so, then we must conclude that deconstruction cannot serve the purpose of rectification or amelioration; it can be of no use to a critical legal or social theory.

There is, however, a fifth account of what deconstructive argument accomplishes. It is the version of deconstructive practice I have advocated in my own writings. It is a version of deconstructive practice specifically designed to be used in a critical theory of law and society. I argue that one deconstructs a conceptual opposition by showing that it is actually a nested opposition (Balkin, $1990 \mathrm{~b})$. A nested opposition is a conceptual opposition in which the two terms 
'contain' each other; that is, they possess simultaneous relationships of difference and similarity which are manifested as we consider them in different contexts of judgment. For example, one term may, in certain contexts, be similar to the other, a special case of the other, logically or practically dependent upon the other, or develop into a form or variant of the other as history progresses. The basic deconstructive point is that all conceptual oppositions can be understood as some form of nested opposition, and that there are often interesting insights to be gained from such a reinterpretation. Hence, deconstructive argument becomes the careful and patient analysis of the grounds of similarity and difference between conceptual oppositions in shifting historical and practical contexts of judgment. It does not dogmatically assert either the essential nature, the effacement, or the undecideability of all conceptual oppositions. Rather, it attempts to discover how conceptual oppositions are related to the contexts that give them force and meaning.

Thus, Derrida's argument about speech and writing can be restated in terms of the theory of nested oppositions. We attempt to see how speech and writing are mutually differentiated and mutually dependent, how they bear relationships of similarity and difference in different contexts of judgment. They are similar in that both have a semiotic function. But their differences reemerge when we look at them in a different way. The goal of the deconstruction is to reveal the contextual nature of practical and theoretical judgment, and to critique acontextual or categorical judgments for their lack of sensitivity to context.

Let us return to the example of the opposition between apartheid or Jim Crow on the one hand, and racial equality on the other. To analyze this opposition as a nested opposition, we might ask whether there are features of apartheid that have unexpected commonalities with particular theories of racial equality, and whether discovery of these similarities can assist our legal and social critiques. Hence we might want to ask the following questions.

First, does the pursuit of racial equality permit or even require, in some circumstances and contexts, racial preferences, or other government distinctions based on race? For example, in the United States, is the pursuit of racial equality consistent with the continued existence of historically black colleges, and does it require race conscious affirmative action programs? If the answer to these questions is yes, then we have discovered a ground of similarity between the two sides of this conceptual opposition. But this does not mean that there is no difference at all between apartheid and the pursuit of racial equality. Our goal is not to efface the distinction between them, but rather to discover appropriate ways of thinking about their similarities and their differences. Thus, what differentiates a system of apartheid or Jim Crow from the pursuit of racial equality may not be the presence of racial distinctions in public decision making, but something else - for example, the presence of racial subordination, or the state's decision to replicate or foster private beliefs about white supremacy and black inferiority. The goal of this analysis is to change our view of the real issues involved, by discovering relevant grounds of similarity and difference. Such an analysis, in turn, will lead to new concepts, categories and distinctions that can be further deconstructed. 
Second, do some theories of racial equality, in practice, lead to or maintain the sort of unjust racial separation and subordination we ordinarily associate with apartheid or Jim Crow? For example, do certain theories of racial equality (for example, purely formal theories of colorblindness or theories which restrict actionable discrimination to intentional racial animus) produce or perpetuate residential racial segregation and differential access to education, jobs, status and other social goods? In other words, do some conceptions of racial equality produce or maintain racial subordination by other means? If so, then they have important similarities to systems of apartheid, and these similarities can serve as the basis of a critique. Here the goal of the deconstruction is to discover hidden (and sometimes embarrassing) connections between practices which go by different names.

\section{Deconstructive Argument as a Rhetorical Practice}

This example shows that the deconstruction of conceptual oppositions is by no means a scientific or algorithmic process. It is informed by the values and commitments of the individual deconstructor, and the directions she chooses to investigate. The above discussion was informed by a set of egalitarian assumptions about race that most people would describe as 'to the left'. A person with a different politics might ask very different questions, and discover very different things through a deconstructive analysis. For example, a conservative opponent of affirmative action might argue that there are greater similarities between egalitarian policies and apartheid or the Nuremburg Laws in Nazi Germany than the left wants to admit. So the target of deconstruction, and the way that the particular deconstructive argument is wielded, may vary with the moral and political commitments of the deconstructor.

There are several reasons for this result. First, when people deconstruct texts, they select certain texts and aspects of texts to critique while leaving others untouched. Thus, Jacques Derrida has used deconstruction to attack apartheid and to defend Paul de Man from what he believes to be unjust criticism (Derrida, 1985, 1989). He has not used deconstruction to attack Paul de Man and defend apartheid. However, there is nothing in the nature of the deconstructive techniques of reading that Derrida employs that prevents this. It is simply that he has particular reasons for deconstructing some texts and positions, and leaving others alone. These reasons may have much to do with the deconstructor's preexisting moral and political commitments, even though these may, in turn, be altered through the process of deconstruction.

Second, although deconstructive analysis is potentially endless, our own deconstructive arguments must come to an end at some point. We cease deconstructing when we feel that we have achieved sufficient enlightenment from the text or conceptual scheme we have deconstructed. This choice of when to stop may also be informed by our moral and political commitments, although once again these may be changed through the process of deconstruction.

Thus, each deconstructive argument must be understood in terms of its 
partiality and selectivity. The human practice of deconstructive argument is always framed and limited both by what it chooses to deconstruct and what it chooses to leave unexamined; both by where it begins its critique and where it ends its analysis.

Although this selectivity may be shaped by personal interest or ideology, it is largely driven by practical necessity. We do not have infinite time to pursue our deconstructive analyses; hence we must begin somewhere and end somewhere. Although our deconstructive arguments destabilize distinctions and conceptual oppositions, they themselves must rely on distinctions and conceptual oppositions, otherwise they could not be expressed in language and understood by others. Thus, no deconstructive argument destabilizes all of the conceptual structures in language or culture at once; for every distinction it deconstructs it leaves unexamined thousands more.

The inherent partiality and limitations of human deconstructive practice explain why deconstructive arguments can be used for many different political and moral purposes. In this sense deconstructive argument shares much in common with rhetoric. As Aristotle (1991: Book I, sec. 4, at 1355a) pointed out, the orator always takes large portions of her audience's beliefs for granted and does not try to contest them. Instead, she focuses on specific questions and makes use of beliefs and attitudes that she and her audience hold in common. Some of these beliefs may be only partially correct, while others may even be the result of unthinking acceptance of community norms. Nevertheless, the advocate refrains from attacking them, because they actually assist her in making her argument.

Because our limited deconstructive arguments are forms of rhetoric, the ethics of deconstruction become very similar to the ethics of rhetoric generally. Derrida himself has scoffed at the idea that deconstruction can be used for an evil or unjust purpose (1989:827); but it does not take very much effort to show that deconstructive arguments about justice can be offered in opposing directions (for examples see Balkin, 1990a, 1994). This is hardly surprising, once we understand deconstructive argument as a form of rhetoric.

The charge levelled against rhetoric has always been that, because it can serve both good and bad purposes, it can be used to mislead people, to induce evil courses of action, or to justify wicked things. Nevertheless, we might defend deconstructive argument in the same way that Aristotle defended rhetoric generally: although deconstructive argument can be used for good or for ill, this does not mean that it cannot be a useful part of public life. It simply means that each of us becomes responsible for the ways in which he or she uses deconstructive argument. The limited and partial use of deconstructive argument available to human intelligence will not lead us inexorably to justice. Nevertheless, used rightly, it can assist us in our critical endeavors.

Deconstructive Argument and the Transcendental Value of JUSTICE

So far I have stressed that deconstructive arguments are always limited encounters 
with the many potentially deconstructible features of law, language and culture. That is why the human practice of deconstructive argument is a rhetorical practice. We might put this point another way: let us call the deconstructibility of human law, language, and culture 'Deconstruction'. So expressed, 'Deconstruction' is not a method or a set of beliefs, but rather a fact about or feature of human culture. Then we might say that the rhetorical practice of deconstructive argument is a limited use of Deconstruction. It is not identical with Deconstruction, but is rather made possible by Deconstruction.

The rhetorical practice of deconstruction is made possible by the deconstructibility of human law, convention and culture. However, what makes a critical deconstruction of human law, convention and culture possible? I shall argue that our belief that human law, convention and culture can be deconstructed for normative purposes must rest on the assumption of transcendental human values - and, in particular, a transcendental value of justice.

We deconstruct law for critical purposes because of a perceived inadequation between law and justice - because we seek a justice as yet unrealized in law. Thus, our deconstruction of law assumes a conceptional opposition between law and justice. However, deconstruction asks us to reconceptualize every conceptual opposition as a nested opposition. When we reconceptualize the opposition between law and justice as a nested opposition, we discover that there is in fact a complex relationship of mutual dependence and differentiation between the two.

Laws apportion responsibility, create rights and duties, and provide rules for conduct and social ordering. But law can never achieve perfect justice. Law is always, to some extent and to some degree, unjust. At the same time, our notion of justice can only be articulated and enforced through human laws and conventions. We may have a notion of a justice that always escapes law and convention, but the only tools we have to express and enforce our idea are human laws and human conventions. Our conception of the just relies for its articulation and enforcement on the imperfect laws, conventions and cultural norms from which it must always be distinguished.

So we come to this conclusion: human law, culture, and convention are never perfectly just, but justice needs human law, culture and convention to be articulated and enforced. There is a fundamental inadequation between our sense of justice and the products of culture, but we can only express this inadequation through the cultural means at our disposal.

This nested opposition between law and justice takes us in unexpected directions. If human legal creations are always to some degree unjust, then justice cannot be fully determined by any positive norms of human law, culture or convention, for these positive norms must also fall short of our value of justice. We must think of our value of justice as an insatiable demand that can never be fulfilled by human law. In short, we must postulate a human value of justice which transcends each and every example of justice in human law, culture and convention. In this way our deconstructive argument brings us to a transcendental value of justice. Thus, the normative use of deconstruction becomes what I call 'transcendental' deconstruction, because it must presume 
the existence of transcendental human values articulated in culture but never adequately captured by culture.

The idea of 'transcendental' values is traditionally associated with Plato and his theory of Forms. However, the transcendental value of justice is quite different from the Form of justice celebrated in the Republic. We are not concerned here with an Idea of determinate content that exists separate and apart from human law, culture and convention. Rather, we are speaking of an insatiable yearning or longing for justice lodged in the human heart. The value of justice is an aspect of the inexhaustible human urge to evaluate, an urge that can never be fully articulated by the positive norms of human culture. So our transcendent value of justice is not a determinate model that human law strives but fails to copy. It is an inchoate, indeterminate and indefinite drive that acts as a goad rather than as a guide. To act justly we do not copy a fixed prototype of the just or measure our actions by a determinate standard of justice; instead, we must construct just institutions in response to the inchoate and indefinite demand of justice. Hence, our laws are imperfect not because they are bad copies of a determinate Form of justice, but because we must articulate our insatiable longing for justice in concrete institutions, and our constructions can never be identical with the longings which inspire them. ${ }^{3}$

We can now connect this argument with the earlier distinction we made between the rhetorical practice of deconstruction and Deconstruction itself. The transcendental conception of deconstruction assumes an essential inadequation between human values like justice and their articulations in human law, culture and convention. This inadequation between culture and value is Deconstruction itself. It is what makes human law, language and culture deconstructible. The rhetorical practice of deconstructive argument makes use of and demonstrates this inadequation in legal and social conceptions. Thus, to deconstruct a legal or social conception is to show, in a limited way, that it partakes in the fundamental chasm between transcendental human values and positive human culture. This rhetorical use of Deconstruction is always and necessarily partial and incomplete. Just as human law cannot be equated with justice, neither can the rhetorical practice of deconstructive argument be identified with Deconstruction itself.

We now see how Derrida's mystical pronouncements about the relationship between deconstruction and justice are both appropriate and mistaken. Derrida argues that justice is an infinite demand, and that the experience of justice is an experience of the impossible (Derrida, 1990:947-9). So we have argued: because justice is a transcendent human value, it can never be fully realized in positive law. The deficiency between law and justice is a special case of the fundamental inadequation between value and culture, a gap or chasm we have called Deconstruction.

On the other hand, Derrida is quite wrong to equate Deconstruction with this impossible value of justice. To be sure, human beings cannot fully articulate the inadequation between law and justice in their deconstructive arguments, so the rhetorical practice of deconstruction is necessarily limited; it cannot be identical to Deconstruction itself. Yet Deconstruction itself is not impossible; it is the very predicament of human culture. 
Although Derrida might like to demonstrate the inherent worth of Deconstruction by identifying it with justice (1990: 945), Deconstruction and justice are by no means the same thing. Juctice is a transcendent value lodged in the human heart, an incurable longing that demands articulation in human culture but is never satisfied by its products. Deconstruction, on the other hand, is a sort of interval between this indeterminate longing and its partial and imperfect realizations in human culture. Deconstruction is not justice, and deconstructive argument is not necessarily just. Indeed, deconstructive theory reminds us that the pursuit of justice is neverending. Nevertheless, as I have tried to show in this essay, deconstructive arguments, properly understood and employed, can form part of a critical theory of law and society. Deconstructive practice can escape the abyss of normative nihilism if it becomes transcendental deconstruction; so conceived, it can assist us in the pursuit of the just.

\section{NOTES}

My thanks to Sandy Levinson and Austin Sarat for their comments on previous drafts of this article, and to Tom Seung, who has greatly influenced the ideas presented here.

1. Because deconstruction is justice, and because justice is impossible, deconstruction is impossible. However, the undeconstructibility of justice and the deconstructibility of law make deconstruction possible. Hence deconstruction is both possible and impossible.

2. For example, Pierre Schlag has argued that deconstruction should be understood in this way, and has specifically attacked the sort of critical employment of deconstruction I advocate here (see Schlag, 1990).

3. These points are developed more fully in Balkin (1994). See also Seung (1990).

\section{REFERENCES}

Aristotle (1991) On Rhetoric, Book 1, George A. Kennedy (trans.). Oxford: Oxford University Press.

Balkin, J. M. (1990a) 'Tradition, Betrayal, and the Politics of Deconstruction', Cardozo Law Review 11:1613-30.

Balkin, J. M. (1990b) 'Nested Oppositions', Yale Law Joumal 99: 1669-705.

Balkin, J. M. (1994) 'Transcendental Deconstruction, Transcendent Justice', Michigan Law Review 92:1131-86.

Derrida, Jacques (1977) Of Grammatology. Baltimore, MD: Johns Hopkins University Press.

Derrida, Jacques (1981a) Positions. Chicago, IL: University of Chicago Press.

Derrida, Jacques (1981b) 'Plato's Pharmacy', pp. 61-155 in Dissemination. Chicago, IL: University of Chicago Press.

Derrida, Jacques (1985) 'Racism's Last Word', pp. 329-38 in H. L. Gates, Jr (ed.), 'Race' Writing and Difference. Chicago, IL: University of Chicago Press.

Derrida, Jacques (1989) 'Biodegradables: Seven Literary Fragments', Critical Inquiry 15:812-73.

Derrida, Jacques (1990) 'Force of Law: The "Mystical Foundation of Authority"', Cardozo Law Review 11:919-1045. 
Schlag, Pierre (1990) "LLe Hors de Texte, C'est Moi": The Politics of Form and the Domestication of Deconstruction', Cardozo Law Review 11:1631-74.

Seung, T. K. (1990) Intuition and Construction: The Foundation of Normative Theory. New Haven, CT: Yale University Press.

Seung, T. K. (1994) Kant's Platonic Revolution in Moral and Political Philosophy. Baltimore, MD: Johns Hopkins University Press. 